\title{
Analysis and simulation of the circulation pump operation
}

\author{
Michat Fijewski ${ }^{1, *}$, Iwona Polarczyk ${ }^{1}$, and Joanna Paduchowska ${ }^{1}$ \\ ${ }^{1}$ Wroclaw University of Science and Technology, Faculty of Environmental Engineering, \\ Wybrzeze Wyspianskiego 27, 50-370 Wroclaw
}

\begin{abstract}
The operation of the circulation installation has a significant impact on the energy efficiency of the building and it contributes to its reduction. The article refers to the actual measurement data obtained from the measurements of the domestic hot water (DHW) preparation system in a multi-family residential building in Wroclaw. On their basis, various possibilities of controlling the operation of the circulation installation without reducing the comfort of DHW operation system were presented and simulated. The results are illustrated in the form of measurable savings in energy consumption and related costs.
\end{abstract}

\section{Introduction}

In systems with central domestic hot water (DHW) preparation the points of DHW use are generally distant from the place where the water is heated, they may be located even up to several dozen meters away. According to the Polish regulations [1], each part of the DHW installation with a volume above $3 \mathrm{dm}^{3}$ must have a circulation system that ensures replacement of water in the DHW system in the absence of DHW consumption.

Circulation installation ensures comfort of using DHW. However, this comfort results in additional costs. Permanent heating of circulating water $(\mathrm{CW})$ generates costs of heat and electricity consumption by lowering the indicators for buildings'energy performance $[2,3]$. During the day there are periods, up to a few hours long, in which DHW consumption stops completely while the hot water circuit continuously extracts heat in order to maintain constant water temperature. In this case, one of the methods to reduce energy consumption can be the appropriate control of the circulating pump (CP).

The use of CP control is one of the elements supposed to improve the energy efficiency of a building, meeting the requirements of Directive 2018/844 of the European Parliament and of the Council (EU) of 30 May 2018 [4] on the energy performance of buildings (EPBD) and Directive 2012/27/EU on energy efficiency (EED) of 19 June 2018. It puts great emphasis on the widespread use of intelligent technologies and automation in buildings. To check the possibilities of implementing the Directive [4] and the real benefits of using such a control, the analysis and theoretical simulation of the CP's operation were performed. For this purpose, however, the actual results of measurements of the DHW installation and the DHW preparation system were made in a multi-family residential

*Corresponding author: michal.fijewski@pwr.edu.pl 
building located in Wrocław. It is a building with 5 above-ground storeys. The building had a thermo-modernization with the replacement of the central heating and DHW piping. The internal water supply was made entirely of polypropylene pipes. The DHW preparation system operates in a system with DHW accumulation with a heat exchanger and a pump-loaded storage tank. The circulation pump operates in a continuous cycle. It is a one-stage pump with a three-phase electric motor.

The operation of the circulating pump installed in a real, used residential building was analysed. The possibilities of using control systems to enable the CP in periods of its increased demand were determined and the efficiency of the $\mathrm{CP}$ was switched off or decreased at the time when the DHW installation was in use. It was assumed that the $\mathrm{CP}$ will be equipped with a control device taking into account the actual nature of DHW intake by users. The circulation system will work during the periods of the day when DHW is not used (readiness for DHW installations) which results in the rational management of electricity and heat. Three ways of controlling the circulation pump operation aimed at reducing the current operating costs have been presented and analysed.

The simulation and analysis of the CP operation, made on the basis of measurements, was limited to one building and one day, due to the scope of the article.

\section{Simulation of circulation pump operation}

\subsection{Simulation of circulation pump operation based on the temperature of the circulating water}

Considering the way of distributing DHW pipes, their ambient temperature, the type of material used for the installation or the type of insulation used, it was found that it may take from several to several dozens minutes before the DHW temperature in pipes decreases (Fig. 1). The control of the pump operation based on the circulating water temperature was analysed. The task of the considered automatic control system is to start the circulation pump after reaching the required minimum $\mathrm{CW}$ temperature regardless of the ongoing use of DHW. Three variants were considered:

- Variant 1: Start the $\mathrm{CP}$ at a $\mathrm{CW}$ temperature of $35^{\circ} \mathrm{C}$

- Variant 2: Start the $\mathrm{CP}$ at a $\mathrm{CW}$ temperature of $30^{\circ} \mathrm{C}$

- Variant 3: Start the $\mathrm{CP}$ at a $\mathrm{CW}$ temperature of $25^{\circ} \mathrm{C}$

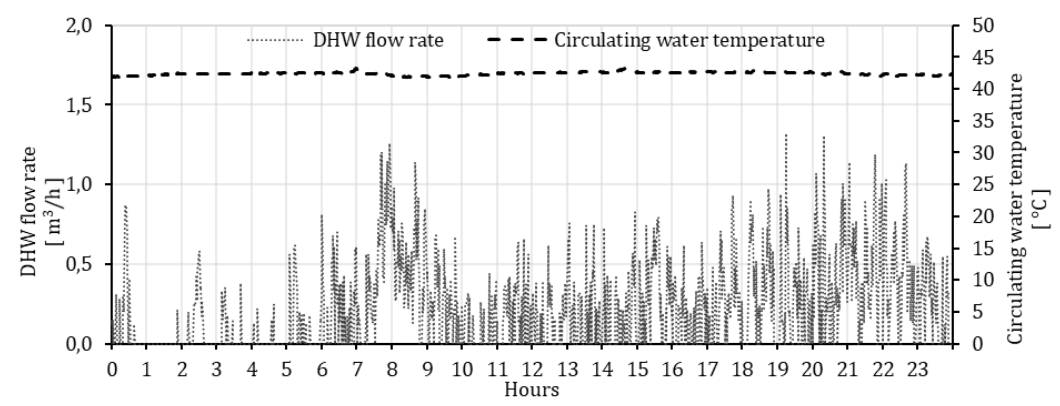

Fig. 1. The measurement carried out DHW flow rate and circulating water temperature at actual, continuous operation of the circulating pump.

Option 3 is an extreme variant, which most users of DHW would not agree to, due to the typical preferences regarding the temperature of DHW. According to the literature data, the preferred DHW temperature intended for dishwashing is from $35^{\circ} \mathrm{C}$ to $54^{\circ} \mathrm{C}$, while the 
DHW temperature intended for bathing should be between $31^{\circ} \mathrm{C}$ and $46^{\circ} \mathrm{C}$ [5]. Therefore, this option was allowed for analysis, in order to estimate the impact of the operating time of the circulation installation on operating costs. Figures 2-4 present the results of the $\mathrm{CP}$ simulation through the example of a daily DHW flow rate in a residential building located in Wroclaw.

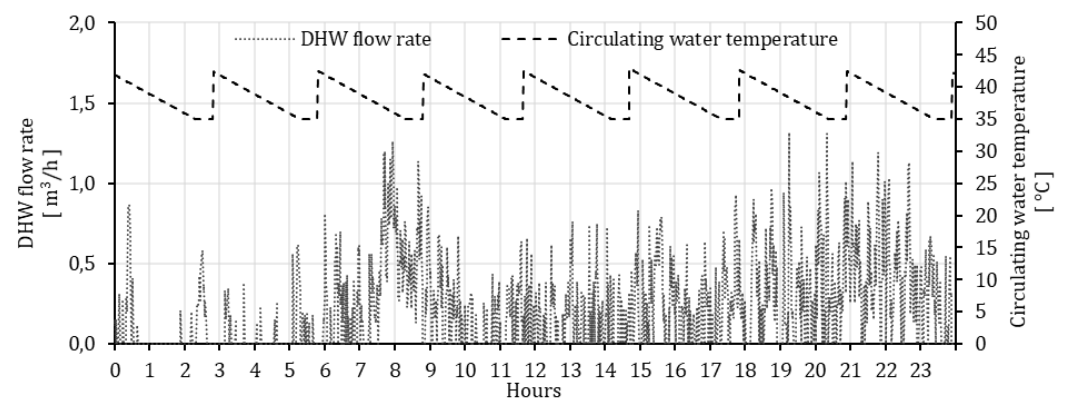

Fig. 2. Variant 1: Suggested characteristics of the $\mathrm{CP}$ operation at a $\mathrm{CW}$ temperature of $35^{\circ} \mathrm{C}$.

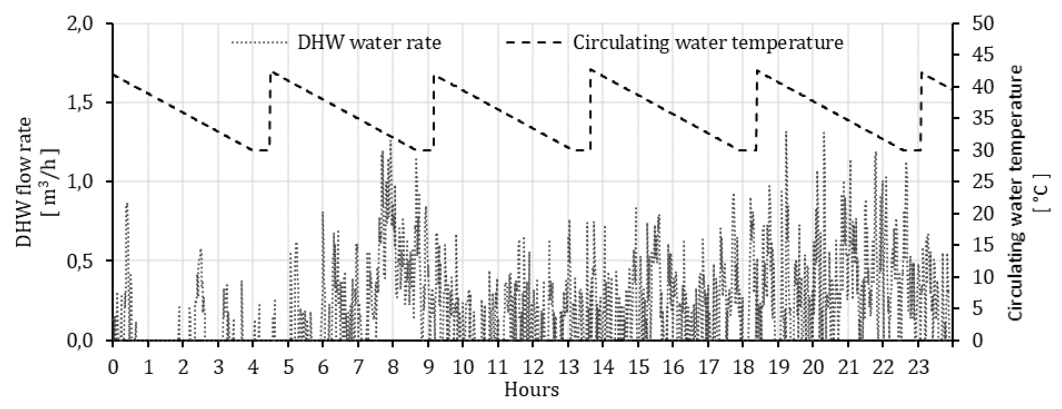

Fig. 3. Variant 2: Suggested characteristics of the $\mathrm{CP}$ operation at a $\mathrm{CW}$ temperature of $30^{\circ} \mathrm{C}$.

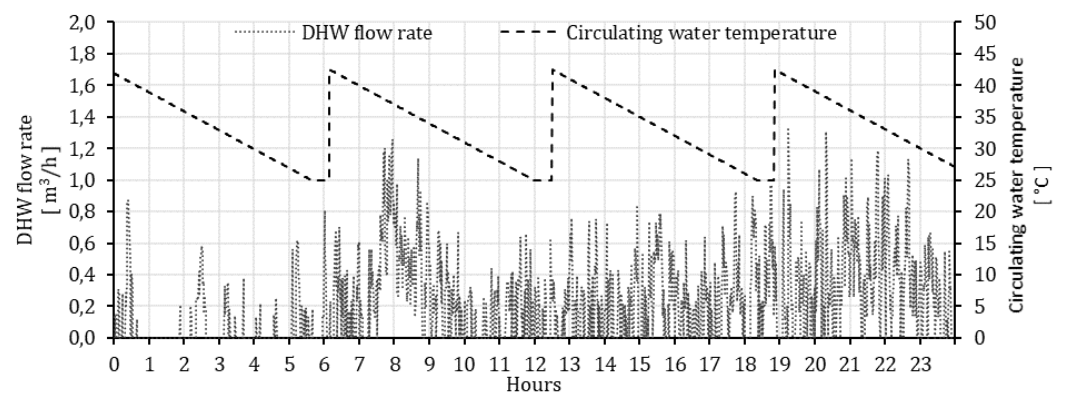

Fig. 4. Variant 3: Suggested characteristics of the $\mathrm{CP}$ operation at a $\mathrm{CW}$ temperature of $25^{\circ} \mathrm{C}$.

In Figure 5, 3 variants of the CP simulation were compared. A summary of the heat demand required to heat the $\mathrm{CW}$ for all cases is presented. As the variant " 0 ", the actual state of operation of the circulation installation is presented without any control. 
Table 1. Comparison of the suggested variants of control of the $\mathrm{CP}$ operation.

\begin{tabular}{|c|c|c|c|c|c|c|c|}
\hline \multirow{2}{*}{ Variant } & $\mathbf{C P}$ operation & $\boldsymbol{\tau - 1 0 0 \%}$ & $\boldsymbol{\tau}-\mathbf{0} \%$ & \multicolumn{2}{|c|}{ E - Heat } & \multicolumn{2}{|c|}{ E - Electricity } \\
\cline { 2 - 8 } & On/Off & $\mathbf{h}$ & $\mathbf{h}$ & GJ & PLN & kWh & PLN \\
\hline Variant 0 & continuous & $24: 00$ & $00: 00$ & 1.13 & 63.19 & 2.76 & 1.99 \\
\hline Variant 1 & $35 / 42^{\circ} \mathrm{C}$ & $4: 00$ & $20: 00$ & 0.33 & 18.60 & 0.46 & 0.33 \\
\hline Variant 2 & $30 / 42^{\circ} \mathrm{C}$ & $2: 30$ & $21: 30$ & 0.27 & 14.85 & 0.29 & 0.21 \\
\hline Variant 3 & $25 / 42^{\circ} \mathrm{C}$ & $1: 30$ & $22: 30$ & 0.20 & 11.16 & 0.17 & 0.12 \\
\hline
\end{tabular}

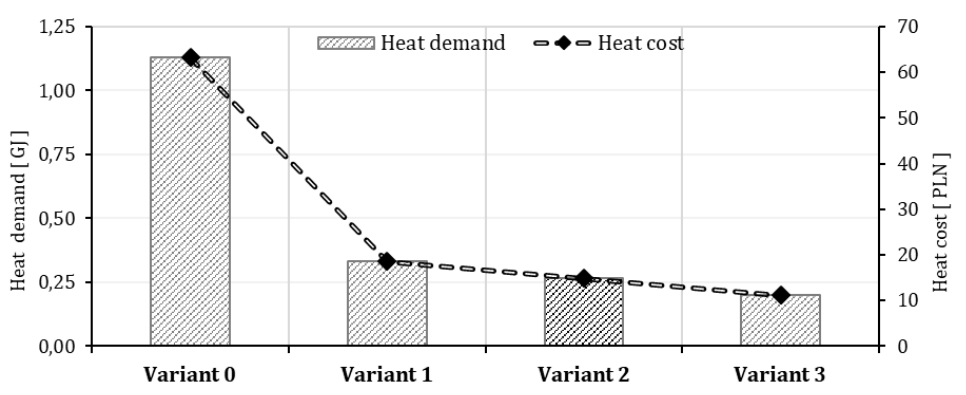

Fig. 5. Comparison of heat demand and energy cost required to heat the circulating water in suggested CP simulation variants.

\subsection{Simulation of circulation pump operation based on the DHW flow rate characteristics}

While analysing the characteristics of DHW flow it can be concluded that users of each installation system are subject to certain constant habits. Throughout the day periods in which the work of the system is continuous can be distinguished. There are DHW flows that are smaller or larger than the average hourly flows. However, the DHW flow is continuous.

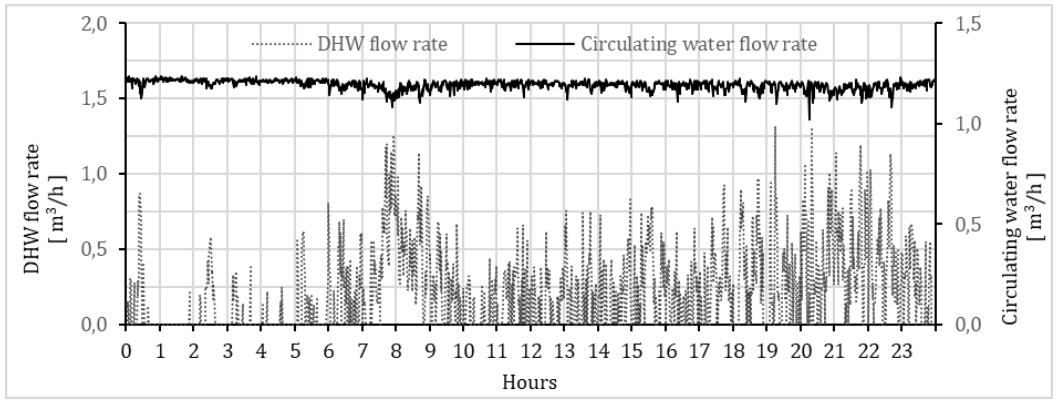

Fig. 6. Actual characteristics of the $\mathrm{CP}$ operation.

There are several minutes breaks between individual DHW flows. They are insufficient for significant cooling of DHW in pipes, below the acceptable DHW temperature preferred by users. Therefore, the automatic control system was analyzed based on the instantaneous DHW flow characteristics. The task of the suggested control method is to reduce the efficiency of the circulation pump to the value of $50 \%$ of the previous state at the moments of DHW flow exceeding the set value in a given unit of time. This will affect the reduction of heat demand by reducing the circulating water flow while maintaining the system readiness for operation. Three variants were considered again, differing from one another when the circulating pump was started with its maximum efficiency: 
- Variant 1: The CP efficiency reduces the continuous DHW consumption in excess of $30 \%$ of the average hourly flow. The CP operation with full efficiency, however, is resumed by the lack of water intake and/or the water intake does not exceed $50 \%$ of the average hourly flow, lasting over 10 minutes.

- Variant 2: CP efficiency is reduced as in option 1. CP operation is resumed at full capacity as in option 1, with the difference that the period of lack of DHW consumption and/or uptake of water not exceeding 50\% of the average hourly flow must last over 20 minutes.

- Variant 3: CP efficiency is reduced as in option 1. CP operation is resumed at full capacity as in option 1, with the difference that the period of lack of DHW consumption and/or uptake of water not exceeding $50 \%$ of the average hourly flow must last over 30 minutes.

The results of the circulation pump simulation are presented below through the example of a daily DHW flow in a building (Fig. 7-9).

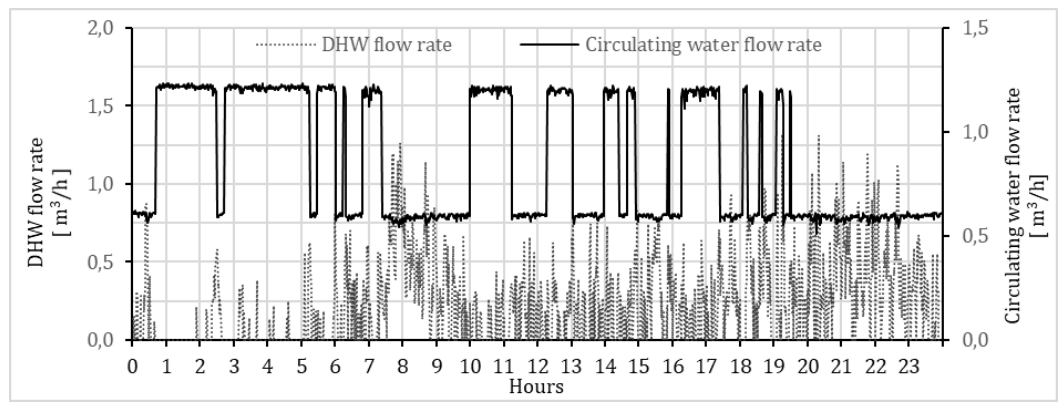

Fig. 7. Variant 1: Suggested characteristics of the CP operation.

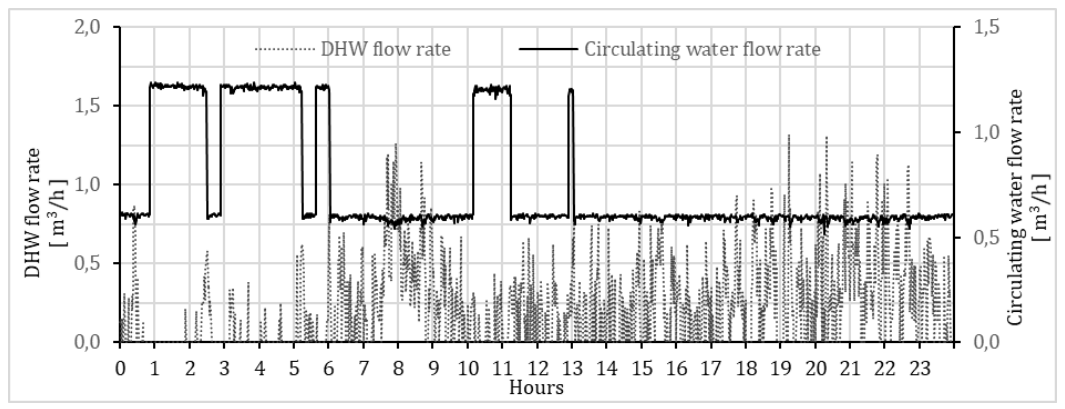

Fig. 8. Variant 2: Suggested characteristics of the CP operation.

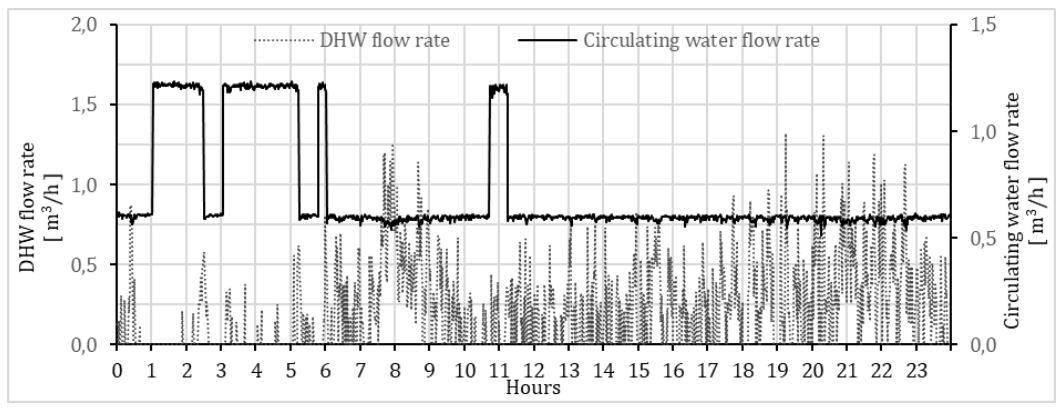

Fig. 9. Variant 3: Suggested characteristics of the $\mathrm{CP}$ operation.

Comparison of the suggested CP simulation variants is shown in Table 2 and in Fig. 10. 
Table 2. Comparison of the suggested CP simulation variants.

\begin{tabular}{|c|c|c|c|c|c|c|c|}
\hline \multirow{2}{*}{ Variant } & CP operation & $\boldsymbol{\tau - 1 0 0 \%}$ & $\boldsymbol{\tau}-\mathbf{5 0} \%$ & \multicolumn{2}{|c|}{ E - Heat } & \multicolumn{2}{|c|}{ E - Electricity } \\
\cline { 2 - 8 } & On/Off & $\mathbf{h}$ & $\mathbf{h}$ & GJ & PLN & kWh & PLN \\
\hline Variant 0 & continuous & $24: 00$ & $00: 00$ & 1.13 & 63.19 & 2.76 & 1.99 \\
\hline Variant 1 & $30 / 3 \mathrm{~min}$ & $9: 54$ & $00: 00$ & 0.49 & 27.17 & 1.14 & 0.82 \\
\hline Variant 2 & $20 / 3 \mathrm{~min}$ & $5: 37$ & $18: 03$ & 0.28 & 15.82 & 0.65 & 0.47 \\
\hline Variant 3 & $10 / 3 \mathrm{~min}$ & $4: 25$ & $19: 05$ & 0.23 & 12.63 & 0.51 & 0.37 \\
\hline
\end{tabular}

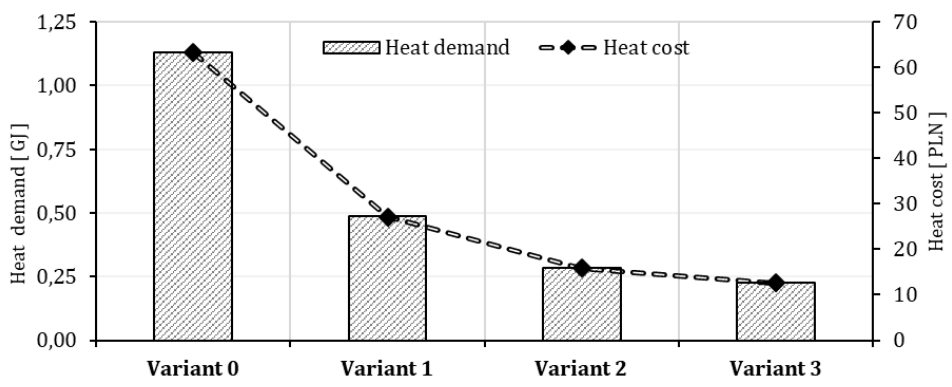

Fig. 10. Comparison of heat demand and energy cost required to heat the circulating water in the suggested $\mathrm{CP}$ simulation variants.

\subsection{Simulation of circulation pump operation based on hourly control}

The analysis of the hot water partition characteristics leads to the conclusion that there are three distinctive states of its operation within 24 hours. Due to the residents' lifestyles during the day the DHW installation is used almost continuously thanks to which a constant circulation of DHW is ensured.

During this period it can be safely ventured that the operation of the circulation system is unnecessary due to the continuous flows of DHW at a temperature ensuring sufficient comfort of use.

In order to minimise the operating costs of the installation and to keep approximately constant costs for the heat and electricity consumed the time of controlling the operation of the circulating pump was considered. The task of the suggested automatic control system is to start the circulation pump operation during the night period when the DHW installation is not in use. This method of control is intended to exclude stagnation of DHW in the pipes for sanitary reasons and to prevent the growth of Legionella bacteria. Three control variants based on switching on and off times of the circulation pump were analysed:

- Variant 1: The circulating pump was switched on at 00:00 and off at 06:00.

- Variant 2: The circulating pump was switched on at 01:00 and off at 06:00.

- Variant 3: The circulating pump was switched on at 02:00 and off at 06:00.

The time of switching the circulation pump on and off was determined on the basis of the DHW flow characteristics. 


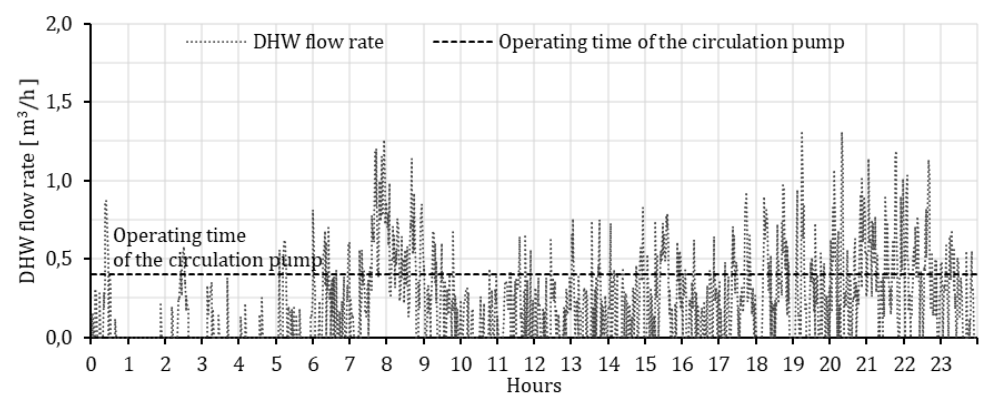

Fig. 11. Actual characteristics of the $\mathrm{CP}$ operation.

The results of the CP operation simulation as the example of a daily DHW flow in the building are shown in Figures 12-14 and comparison of the suggested simulation variants of the circulating pump operation in Figure 15.

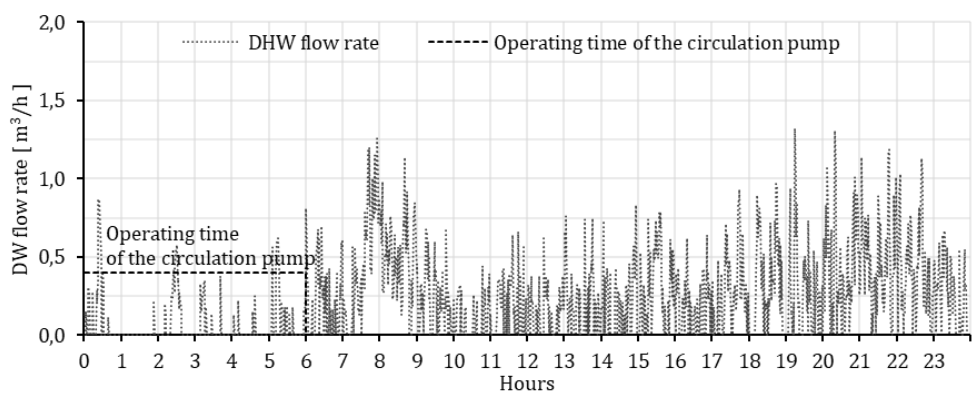

Fig. 12. Variant 1: Suggested characteristics of the CP operation.

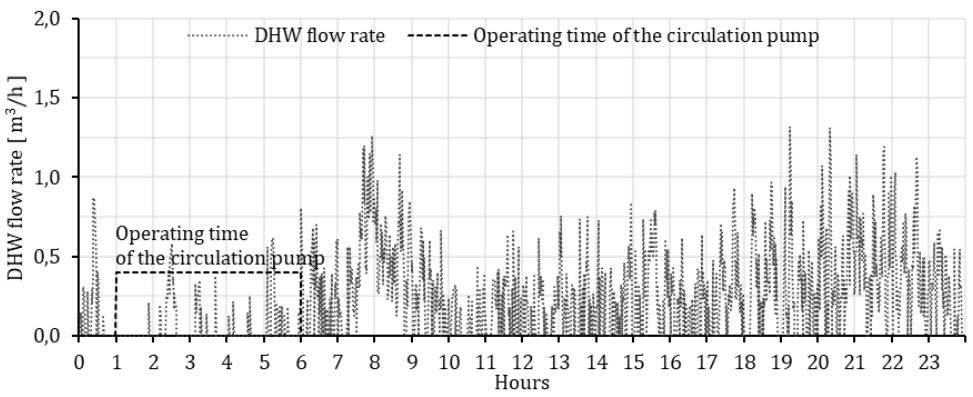

Fig. 13. Variant 2: Suggested characteristics of the CP operation.

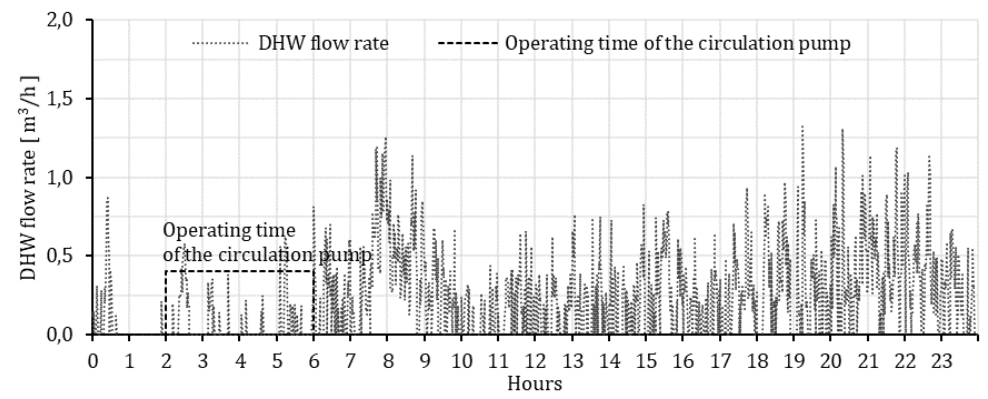

Fig. 14. Variant 3: Suggested characteristics of the CP operation. 
Table 3. Comparison of the suggested CP simulation variants

\begin{tabular}{|c|c|c|c|c|c|c|c|}
\hline \multirow{2}{*}{ Variant } & CP operation & $\boldsymbol{\tau}-\mathbf{1 0 0} \%$ & $\boldsymbol{\tau}-\mathbf{0 \%}$ & \multicolumn{2}{|c|}{ E- Heat } & \multicolumn{2}{|c|}{ E-Electricity } \\
\cline { 2 - 8 } & On/Off & h & h & GJ & PLN & kWh & PLN \\
\hline Variant 0 & continuous & $24: 00$ & $00: 00$ & 1.13 & 63.19 & 2.76 & 1.99 \\
\hline Variant 1 & $00: 00 / 6: 00$ & $6: 00$ & $18: 00$ & 0.30 & 16.89 & 0.69 & 0.50 \\
\hline Variant 2 & $01: 00 / 6: 00$ & $5: 00$ & $19: 00$ & 0.25 & 14.24 & 0.58 & 0.41 \\
\hline Variant 3 & $02: 00 / 6: 00$ & $4: 00$ & $20: 00$ & 0.21 & 11.46 & 0.46 & 0.33 \\
\hline
\end{tabular}

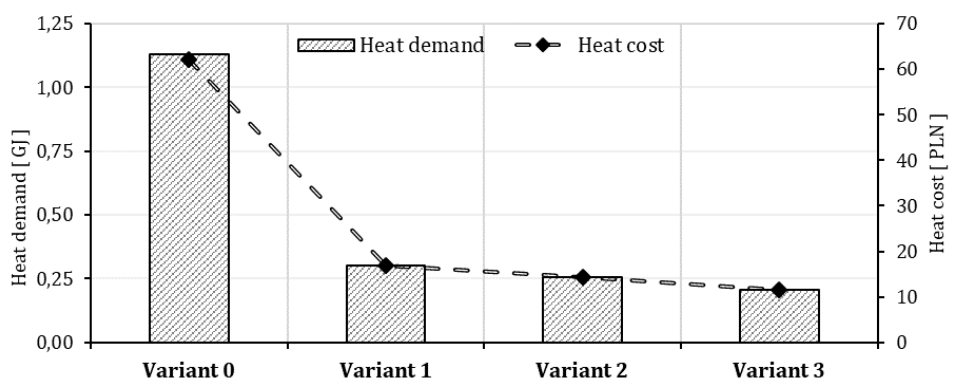

Fig. 15. Comparison of heat demand and energy cost required to heat the circulating water in the suggested $\mathrm{CP}$ simulation variants.

\section{Conclusions}

The task of the circulating installation is to ensure the appropriate DHW temperature in front of the dipping points. The correct design and execution enables users to obtain water at the right temperature after a short time, regardless of the distance of the DHW intake point from the source of DHW preparation system.

Conclusions:

1. The use of the $\mathrm{CP}$ control reduces the energy consumption of the circulating installation by at least $60 \%$. Differences between individual simulation methods in each variant are not significantly large.

2. CP controlling based on the temperature of the circulating water allows for the direct control of the quality (temperature) of the DHW supplied to the recipients.

3. The method of CP control based on the control of the DHW stream is the most universal method that does not require precise knowledge of DHW flow rate characteristics (direct tests). This is a very good way to control the circulation systems, suggested and ready to use already at the design stage of the installation.

4. Controlling the work of a circulation installation based on temporary switch-off is the cheapest solution because of the drivers used. It can be easily applied in existing systems without regulation. The control algorithm can be easily changed and adapted to the nature of the installation.

Which variant is the best? As always, the answer is complex. However, it is possible to find a way to control the circulation installation operation based on the control of the DHW flow for the buildings being designed and the method of control based on the temporary switch-off for existing buildings. 


\section{References}

1. Ordinance of the Minister of Infrastructure of 12 April 2002 on the conditions to be met by buildings and their location (Journal of Laws No. 75 of 2002, Journal of Laws No. 33 of 2003, Journal of Laws No. 109 2004, as amended on 12.03.2009)

2. I. Polarczyk, M. Fijewski, E3S Web of Conferences 22, 00136 (2017)

3. I. Polarczyk, M. Fijewski, E3S Web of Conferences 22, 00137 (2017)

4. Directive (EU) 2018/844 of the European Parliament and of the Council of 30 May 2018 amending Directive 2010/31/EU on the energy performance of buildings and Directive 2012/27/EU on energy efficiency

5. W. Szaflik, Projektowanie instalacji ciepłej wody użytkowej $w$ budynkach mieszkalnych (Szczecin, 2008) 